\title{
Scanning Electron Microscopy (SEM) of Seed Infected with Seed Borne Fungi
}

\author{
A. R. Gulhane, G. K. Giri and Shilpa V. Khambalkar* \\ Sorghum Research Unit, Dr. PDKV, Akola - 444 104, Maharashtra, India \\ *Corresponding author
}

\section{A B S T R A C T}

Keywords

Curvularia lunata,

Drechslera

tetramera, Bipolaris

sorghicola

Article Info

Accepted:

28 June 2018

Available Online:

10 July 2018
The scanning electron micrograph of various fungi growing over sorghum and wheat seeds showed that, the conidia of Curvularia lunata were slightly curved, three septate, central cell were broad having surface ornamentation, darker than the end cell and arranged on sympodially branched conidiophores on sorghum seed. The mycelial structure of Drechslera tetramera on wheat showed network of hyphae, roughed conidiophores and cluster of conidia arranged on geniculate conidiophores. Conidia of Bipolaris sorghicola were smooth walled, straight and slightly curved attached to the geniculate conidiophores. Lytic mycelium of $B$. sorghicola, was also observed on sorghum seed.

\section{Introduction}

\section{Scanning}

Graminicolous spp. such as paddy, wheat, pearl millet and sorghum is the most important crop in India. In recent years the changes of cropping practices in to intensive systems leads rice, wheat, sorghum and pearl millet crop to more diseases problems such as blast, sheath blight, grain, discolouration, grain mould, leaf spot. Curvularia spp. occasionally caused leaf spot in several plants, $C$. lunata has been implicated as one of the most important grain mould in rice, wheat, pearl millet and sorghum. The pathogen causes discolouration on the seed, degenarate endosperm and also infected embryo resulting in almost $100 \%$ loss in variability of seed (Rao and William, 1978). Recently Deshmukh and Raut (1993) confirmed that C. lunata can infect all the part of seeds of sorghum.

Bipolaris sorokiniana causing spot blight is one of the most important foliar pathogens of wheat. Causing several losses in wheat production. It is capable of causing damage from the primary leaf stage, through the plant tends to become more susceptible after flowering. The incidence of $B$. sorokiniana was found highest in grains the leaf blight and seedling blight disease caused by $B$. sorokiniana was reported on leaf of wheat crop (Malekar et al., 2010; Malekar and Main, 
2007; Azad et al., 2009). Twenty seven fungal species associated with rice seed samples among them most prominent fungi was Bipolaris oryzae (82.08\%). The leaf blight/ brown spot caused by Bipolaris oryzae and $C$. lunata were recorded in rice crop (Bharti and Raut, 2009; Archana and Prakash, 2013; Safari and Kaviani, 2008; Kamaluddem et al., 2013).

Seed health study mostly has been conducted to measure yield losses as well as pathogen the aim of this work is to describe morphological and cytological features of vegetative and reproductive structures of fungi observed with the Scanning Electron Microscope (SEM).

\section{Materials and Methods}

The scanning electron microscopy was performed at Department of Metallurgical and Material Engineering, Visvesvaraya National Institute of Technology, Nagpur (Maharashtra). The pure culture of Curvularia, Drechslera and Bipolaris species were inoculated to the seed and incubated for seven days by blotter paper method. The morphological characters of fungi growing over seed was studied through scanning electron microscopy.

\section{Seed inoculation}

Seeds were surface disinfected with mercuric chloride $(0.1 \%)$, washed repeatedly with distilled water and inoculated with pure culture of respective fungi to the entire seed surface. Inoculated seed were incubated for seven days by employing blotter paper method and used for further observations under scanning electron microscope.

\section{SEM observations}

The Curvularia, Drechslera and Bipolaris species infected seed of sorghum and wheat were dehydrated with normal dry air. Infected seeds were fixed with $2 \%$ glutaraldehyde 0.1 $\mathrm{M}$ solution and then treated with $4 \%$ osmium tetra oxide $\left(\mathrm{O}_{\mathrm{s}} \mathrm{O}_{4}\right)$ vapor for two hours respectively. For dehydration step, a serial fixation was used with cold ethanol $(70 \%$ $100 \%$ ) and further it was dried by using vacuum evaporation. Seeds of sorghum and wheat was mounted in aluminium stub, and it was sealed with colloidal silver paste, then sputter-coated with gold particle $(15 \mathrm{~nm}$ thickness). The ready to use preparation of specimens was observed under JEOL (JSM 6380A) SEM. The visual examination of growing structure of fungi over seed was recorded by photography using black and white film.

As observed under JEOL (JSM 6380A) SEM. The visual examination of growing structure of fungi over seed was recorded by photography using black and white film.

\section{Results and Discussion}

The seed borne fungi, Curvularia lunata, Drechslera tetramera and Bipolaris sorghicola growing over the seed of sorghum and wheat were observed under Scanning Electron Microscope (SEM).The Scanning Electron Microscopy showed different development stages of these fungi. The plate 12 showed that Curvularia lunata, Drechslera tetramera and Bipolaris sorghicola were predominantly covered the seed with mycelium and conidiophore bearing conidia. Similarly, colonies of Curvularia lunata produced well developed mycelium on the seed surface.

The mycelium was mostly immerse, forming straight and smooth conidiophore and larger roughened central cell of conidia arranged on sympodially branched conidiophores. In case of sorghum seed, the conidia of Curvularia lunata were slightly curved and three septate. 
Plate.1 Scanning electron micrographs showing conidia and mycelium of Curvularia lunata on surface of wheat seed
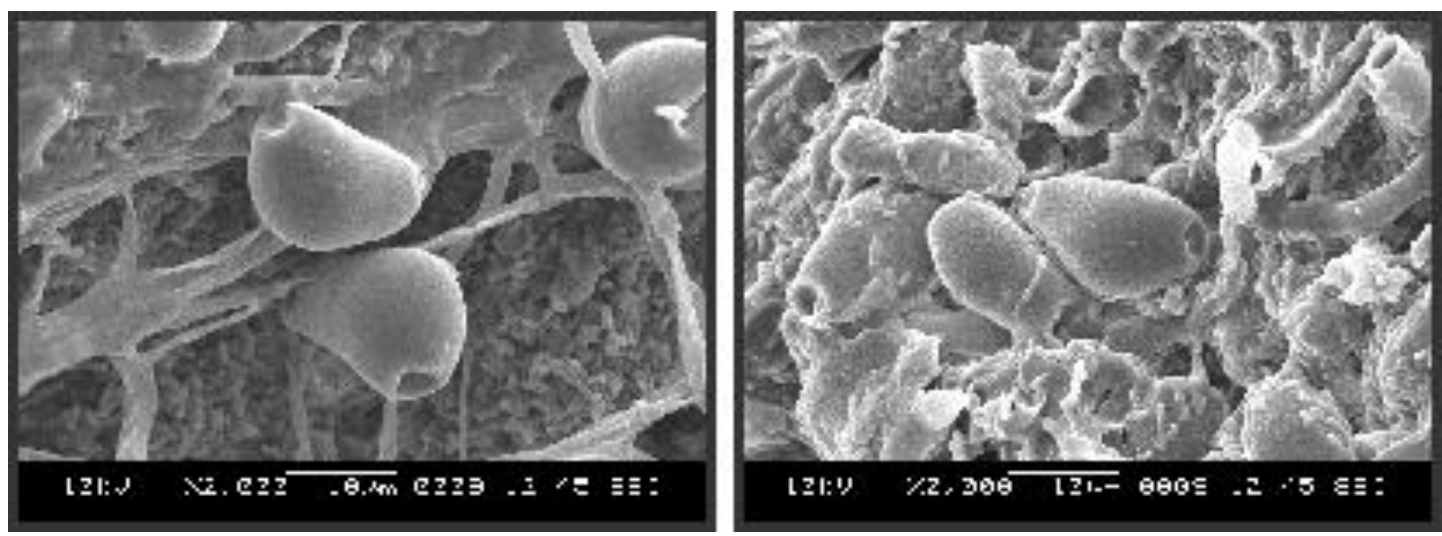

Plate.2 Scanning electron micrographs of Drechslera tetramera growing on surface of wheat seed
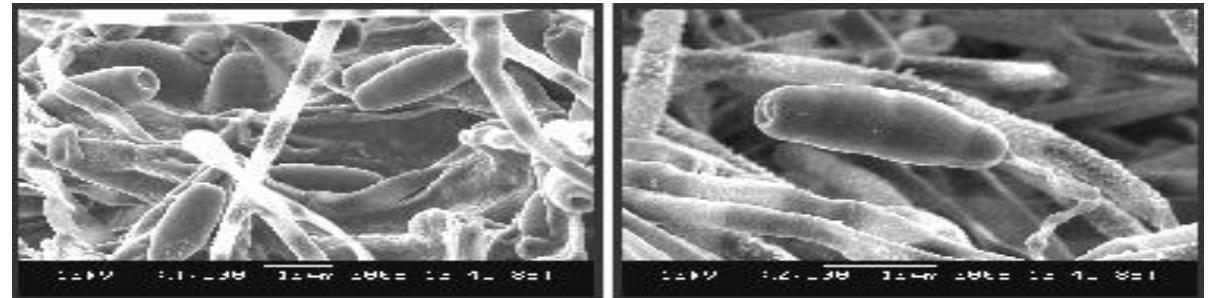

Sicanning electwon micrographs of Drecheler a tetramera showing wo whened. conidiop hore, apical germporres on conidia and germinating contilia
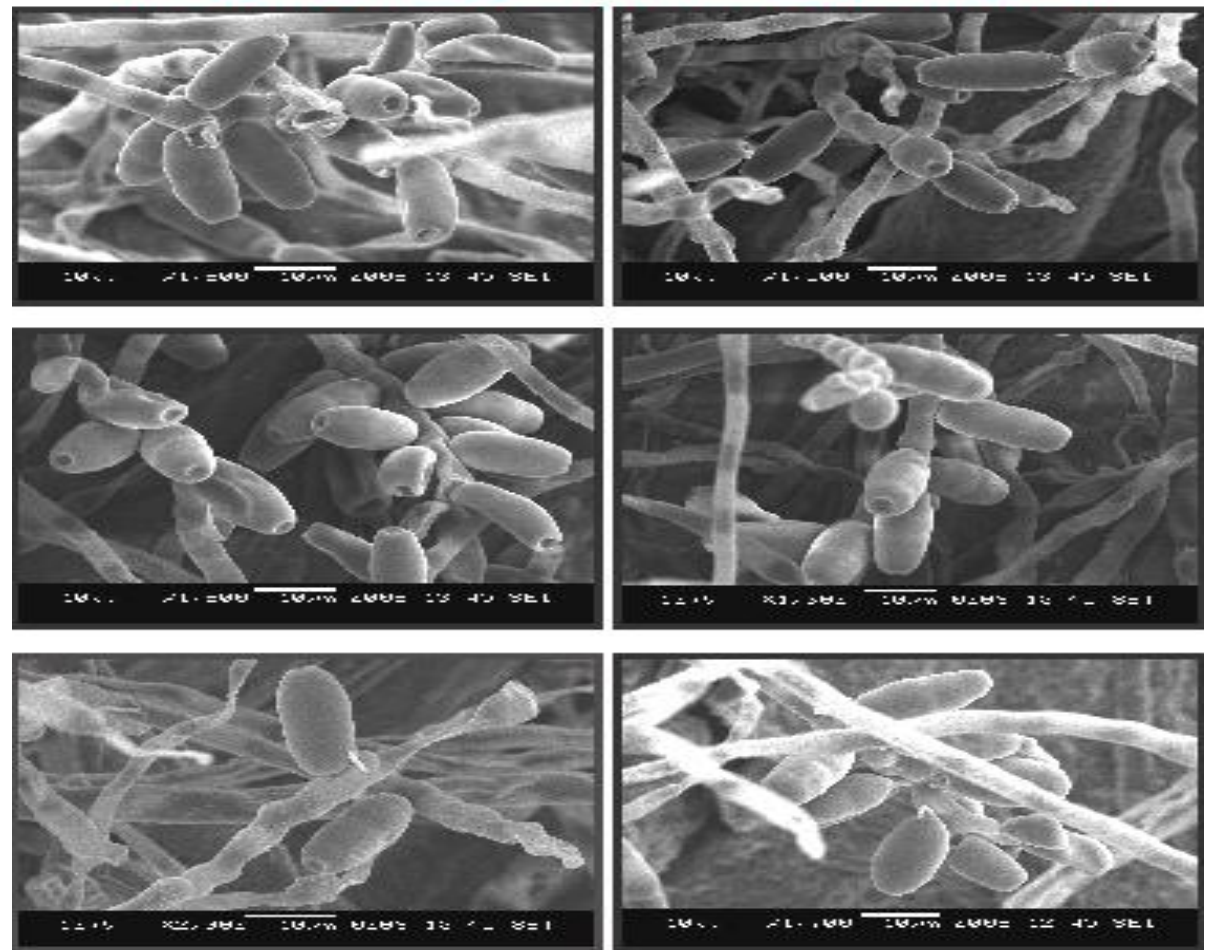

Scanning electron micrographs showing arrangennent of conidia on geniculate conidiop hoore 
Plate.3 Scanning electron micrographs of Bipolaris sorghicola growing on surface of sorghum seed
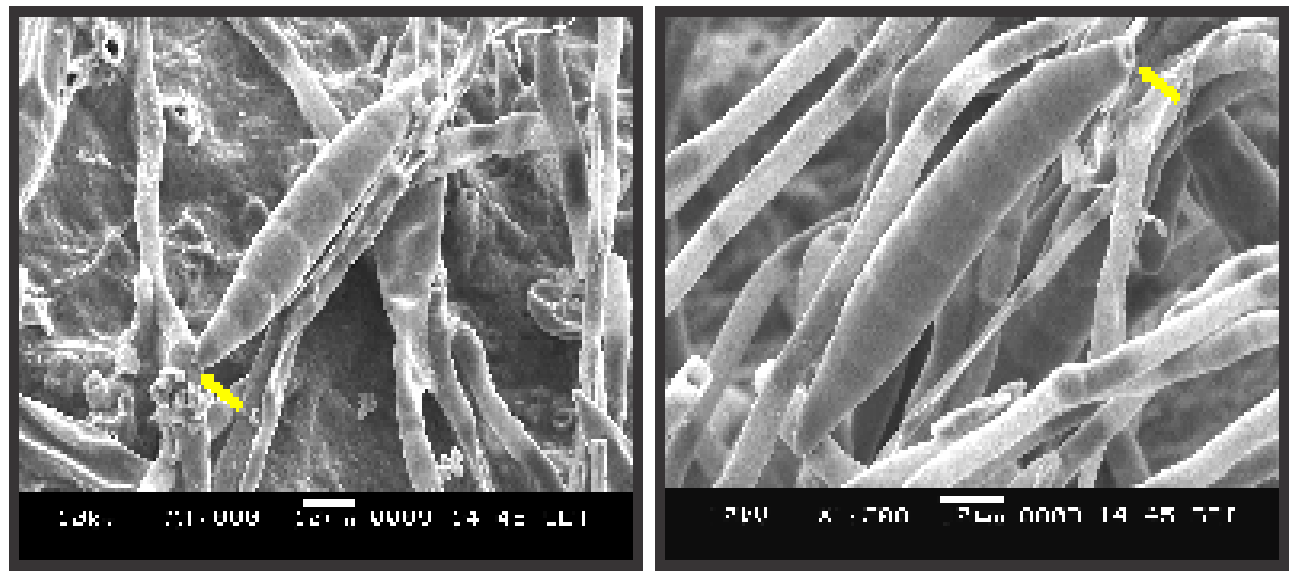

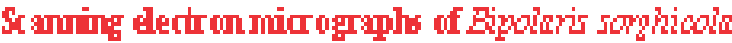
showing coridial septation, attachent uinh conidophore and hilum.
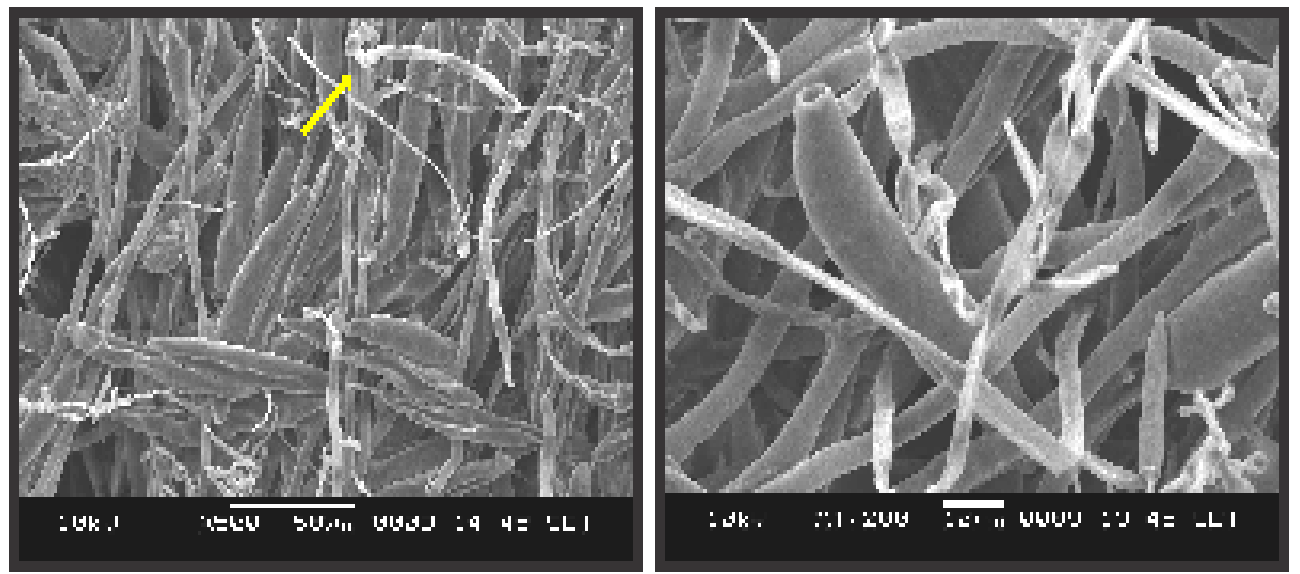

Sc anning electron miarographs shouing conida, geniculate conidiophore andlytic mycelimn of Epolaris sorghicois

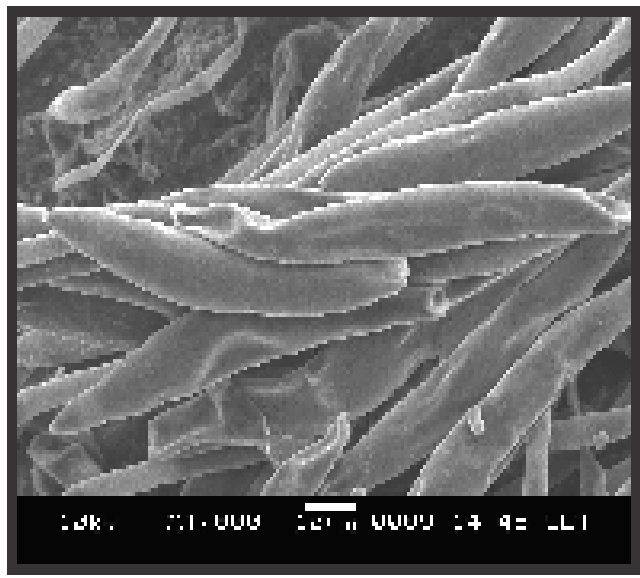

Sc anning electronmiarographs shouing older and senescent conida of Bipolaris sorgincoln 
In general, central cells were broad having surface ornamentation and darker than end cells (Plate 1). Some mature, slightly curved conidia of Curvularia lunata were also being liberated from the conidiophores on surface of wheat seed.

The scanning electron micrograph of mycelial structure of Drechslera tetramera growing on wheat seed showed the network of hyphae and also showed roughened conidiophores, conidia with apical germpors and germinating conidia. A cluster of conidia arranged on geniculate conidiophores were also seen. (Plate 2)

The conidia of Bipolaris sorghicola were smooth walled, straight or slightly curved arranged on geniculate conidiophore. Terminal germ pores were visible on smooth conidia of $B$. sorghichola and the lytic mycelium was also observed on sorghum seed (Plate 3).

The conidial attachment of Bipolaris sorghicola with conidiophores, conidial septation, conidial hilum, and older and senescent conidia were also noticed. Mukherjee et al., (2013) reported that under scanning electron micrograph, the conidia of Curvularia species was developed from septate branched hyphae and conidia were curved shaped, 3 to 4 celled. These findings are also similar with those of Freire et al., (1998) who reported that, conidia of Curvularia pallescens observed under scanning electron micrograph was curved shaped and three septate. The present findings are in accordance with findings of Aggarwal et al., (2002) who also observed the conidia of Bipolaris sorokiniana under scanning electron microscope in the form of smooth walled, terminal germ pores attached with conidiophores. Similar results have also been reported by Domiciano et al., (2013) under scanning electron micrograph, Bipolaris sorokiniana formed a dense network of conidiophores hyphae and conidia formed a germ tube.

Scanning Electronic Microscopy (SEM) of $C$. lunata, B. sorghicola and D. tetramera growing over sorghum and wheat seed revealed the presence of conidial surface ornamentation, roughened conidiophore, senescent conidia, geniculate conidiophore, lytic mycelium, hilum and apical germpore on conidia.

\section{References}

Aggarwal, R, S. Das, D.V. Singh and K.D. Srivastava, 2002. SEM studies on spore morphology and infection process of spot blotch pathogen in wheat. Indian Phytopath. 55(2): 197-199.

Carison, H., U. Stenram, M. Gustafsson and H.B. Jansoon, 1991. Electron microscopy of barley root infection by the fungal pathogen Bipolaris sorokiniana. Canadian J. of Botany. 69(12): 2724-2731.

Domiciano, G.P., F.A. Rodrigues, A.M.N. Guerra and F.X.R. Vale, 2013. Infection process of Bipolaris sorokiniana on wheat leaves is affected by silicon. Trop. Plant Pathol. 38(3).

Falloon, R.E., 1976. Curvularia trifolii as a high temperature turfgrass pathogen. N.Z. Journal of Agricultural Research. 19: 243-248.

Mukherjee, A., A. Bandhyopadhyay and S. Dutta, 2013. New Report of leaf spot disease of Clerodendrum indicum caused by Curvularia lunata. Int. J. Pharm Bio. Sci. 4(3): 808-812.

Singh, U.P., S.K. Singh, Koya Sugawara, J.S. Srivastava, B.K. Sarma and B. Prithiviraj, 2001. Studies on Sclerotium formation in Curvularia species. Mycobiology. 29(3): 154-159. 
Waheeb Heneen and Kerstin Brismar, 1987. Scanning electron microscopy of mature emphasis on grain shrivelling. grains of rye, wheat and triticale with

\section{How to cite this article:}

Gulhane A. R., G. K. Giri and Shilpa V. Khambalkar. 2018. Scanning Electron Microscopy (SEM) of Seed Infected with Seed Borne Fungi. Int.J.Curr.Microbiol.App.Sci. 7(07): 40964101. doi: https://doi.org/10.20546/ijcmas.2018.707.476 